Tropical Journal of Pharmaceutical Research November 2017; 16 (11): 2617-2622

ISSN: $1596-5996$ (print); 1596-9827 (electronic)

(C) Pharmacotherapy Group, Faculty of Pharmacy, University of Benin, Benin City, 300001 Nigeria.

All rights reserved.

Available online at http://www.tjpr.org

Original Research Article

http://dx.doi.org/10.4314/tjpr.v16i11.7

\title{
Effect of $\beta$-nerve growth factor on differentiation of endothelial progenitor cells in rats
}

\author{
Zhong-jing Wang ${ }^{1}$, Zi-hui $\mathrm{Xu}^{1}$, Yu-ming $\mathrm{Li}^{2}$, Sheng Ding ${ }^{1}$, Cai Cheng ${ }^{1}$ and Shi \\ Zhao ${ }^{\text {* }}$ \\ ${ }_{1}^{1}$ Department of Endocrinology, The Central Hospital of Wuhan, ${ }^{2}$ Department of Endocrinology, Union Hospital, Tongji Medical \\ College, Huazhong University of Science and Technology, Wuhan 430022, Hubei, China
}

*For correspondence: Email: zhaoshiwh@163.com

Sent for review: 1 July 2017

Revised accepted: 24 October 2017

\begin{abstract}
Purpose: To investigate the effect of recombinant adenovirus-mediated human $\beta$-nerve growth factor (Ad-EGFP-h $\beta$-NGF) on the differentiation of endothelial progenitor cells (EPCs) in rats.

Methods: The successfully constructed Ad-EGFP-hß-NGF and its negative control Ad-EGFP were infected into the isolated and purified rat EPCs to observe their morphological changes. Enzyme-linked immunosorbent assay (ELISA) was conducted to detect the levels of vascular endothelial growth factor (VEGF), von Willebrand factor (VWF) and basic fibroblast growth factor (bFGF) in different rat EPC culture solutions. Western blot was performed to determine the expression of tyrosine kinase receptor $A$ (TrKA) protein in different groups of EPCs.

Results: Primary fibrous EPCs were converted into epithelium-like cells. After infection with Ad-EGFP$h \beta$-NGF for 1 week, some EPCs became round and exhibited neural stem cell-like changes. The expression levels of VEGF, vWF and bFGF in the Ad-EGFP-h $\beta-N G F$ infection group were significantly higher than those in the control group $(p<0.01)$. TrKA protein in Ad-EGFP-h $\beta$-NGF infection was also significantly up-regulated compared with that in the negative control and blank control groups $(p<0.01)$. Conclusion: $\beta$-NGF up-regulates the expression of TrKA receptor protein and secretion of angiogenic growth factors (i.e., VEGF, vWF and bFGF), thereby promoting the differentiation of rat EPCs, which may contribute to angiopoiesis or vascular repair.
\end{abstract}

Keywords: $\beta$-Nerve growth factor, Endothelial progenitor cells, Angiogenic growth factors, Tyrosine kinase receptor $A$, Cell differentiation

Tropical Journal of Pharmaceutical Research is indexed by Science Citation Index (SciSearch), Scopus, International Pharmaceutical Abstract, Chemical Abstracts, Embase, Index Copernicus, EBSCO, African Index Medicus, JournalSeek, Journal Citation Reports/Science Edition, Directory of Open Access Journals (DOAJ), African Journal Online, Bioline International, Open-J-Gate and Pharmacy Abstracts

\section{INTRODUCTION}

Endothelial progenitor cells (EPCs), also known as angioblasts, are bone marrow-derived stem cells characterised by migration; thus, these cells can further proliferate and differentiate into vascular endothelial cells[1]. EPCs play important roles in vivo to promote vascular regeneration, repair damaged endothelial functions and improve local blood perfusion [2]. Thus, EPCs are clinically significant. According to our previous clinical studies, autologous peripheral blood stem cell transplantation can effectively improve the outcomes of diabetic peripheral vascular disease $[3,4]$.

Nerve growth factor (NGF) is a nerve cell growth regulator that is firstly found amongst neurotrophic factors. NGF contains three subunits (i.e., $\alpha, \beta$ and $\gamma$ ), and the active region is the $\beta$ subunit. $\beta$-NGF is a dimer consisting of two single-strands through noncovalent bonds [5]. 
Recent studies have shown that in addition to its neurotrophic roles, NGF participates in promoting angiogenesis in damaged tissues [6]. In this study, recombinant adenovirus-mediated $\beta$-NGF was infected into rat EPCs to investigate its effects on EPC differentiation by determining whether NGF promotes endothelial regeneration through regulating EPC differentiation.

\section{EXPERIMENTAL}

\section{Reagents and instruments}

Four-week-old male SD rats weighing 60-80 g were provided by the Experimental Animal Center of Tongji Medical College. The following reagents were used in this study: Percoll cell separation solution (Pharmacia, USA), EGM2MV culture medium (Lonza, Switzerland), rabbit anti-human CD34 antibody and isotype control murine IgG1 antibody (Abcam Inc), rabbit antihuman VEGF ELISA assay kit (R\&D, USA), rabbit anti-human vWF ELISA assay kit (China), rabbit anti-human bFGF ELISA assay kit (China), rabbit anti-rat tyrosine kinase receptor $A$ (TrKA; Santa, USA), rabbit anti-rat actin (Santa, USA), secondary antibodies (Beijing Zhongshan) and ECL (Beyotime Biotechnology Co. Ltd). Other reagents were of analytical grade. FACSCalibur flow cytometer (BD Co.), 5810R high-speed lowtemperature centrifuge (Eppendorf Co.) and microplate reader (Bio-Rad, Inc) were also employed.

\section{Isolation and purification of rat EPCs}

The rats were anaesthetised, decapitated and then soaked in $75 \%$ ethanol for $15 \mathrm{~min}$. Afterward, the femur and tibia were sampled and soaked into $0.9 \%$ precooled $\mathrm{NaCl}$ solution (4 $\left.{ }^{\circ} \mathrm{C}\right)$. The marrow cavity was then repeatedly flushed with saline until the rinsing solution was clear. The cells were pipetted evenly and slowly added into centrifuge tubes containing Percoll cell separation solution. This study was approved by Animal Ethics Committee of Huazhong University of Science and Technology (ref no. 2016005022). All the experimental procedures were performed in accordance with the International Guidelines for Care and Use of Laboratory Animals [7].

The volume ratio of the rinsing solution to the separation solution was $2: 1$. After centrifugation at $2500 \mathrm{rpm}$ for $20 \mathrm{~min}$, the milky cloudy mononuclear cells (MNCs) in the middle of the centrifuge tube were gently sucked and moved into a new tube and then rinsed with PBS twice (1300 r/min, $8 \mathrm{~min}$ ). Subsequently, 20\% FBScontaining EBM-2MV culture medium was used to resuspend the cells and then gently pipetted repeatedly to make a single cell suspension.

The cell suspension was seeded into $6 \mathrm{~cm}$ dish with a density of $1 \times 10^{6}$ cells $/ \mathrm{mL}$ and incubated at $37{ }^{\circ} \mathrm{C}$ in $5 \% \mathrm{CO}_{2}$ and saturated humidity. After 4 days, the medium was totally changed for the first time. The suspended cells were discarded, and the rest of the cells were stored for culture. The medium was changed every 3 days. Meanwhile, the morphological changes of the cells were observed. On the 14th day (the cells grew to $80 \%$ confluence), $0.25 \%$ trypsin was used to digest the dish wall-adherent cells. The cells were also passaged (1:2), and the culture was continued until the 28th day.

\section{Infection}

Adenovirus-mediated human $\beta$-nerve growth factor (Ad-EGFP-h $\beta$-NGF) and its negative control Ad-EGFP were provided by Dr Jianing Wang of the Clinical College of Hubei Medical College. The EPCs of rats cultured until the $28^{\text {th }}$ day were divided into three groups and infected with Ad-EGFP-h $\beta-N G F$ and Ad-EGFP with 100 multiplicity of infection. Meanwhile, the blank control group was prepared. After $48 \mathrm{~h}$ infection, the cell morphological changes were continuously observed.

\section{Expression and detection of TrKA protein through Western blot}

After $48 \mathrm{~h}$ infection, the cells were washed with precooled PBS, and the supernatant was discarded. Precooled $\left(4^{\circ} \mathrm{C}\right)$ tissue protein extract solution (50 mM Tris- $\mathrm{HCl}$, pH 8.0, $150 \mathrm{mM} \mathrm{NaCl}$, $1 \%$ NP-40, $100 \mu \mathrm{g} / \mathrm{ml}$ PMSF, $0.5 \%$ deoxycholate, $0.02 \%$ sodium azide, and $1 \mu \mathrm{g} / \mathrm{ml}$ aprotinin) was added, and the mixture was then incubated on ice for $15 \mathrm{~min}$. The cells were then lysed on ice via ultrasound. The supernatant (obtained by $10 \mathrm{~min}$ centrifugation at $4^{\circ} \mathrm{C}$ and $12000 \mathrm{rpm}$ ) was used to determine the protein concentration with BCA assay, and the protein detected using $12 \%$ SDS-PAGE electrophoresis, membrane transfer, and incubation with primary antibodies (TrKA 1:2000, Actin 1:10000) and secondary antibody (1:10000). ECL chemiluminescence method was used for the coloration, and Syngene gel imaging system was employed to photograph, record and analyse the results.

\section{Detection of VEGF, VWF and bFGF in the culture supernatant by ELISA}

After the cells were infected for 6 days, the culture supernatant was collected and 
centrifuged at room temperature $(2000 \mathrm{rpm}, 3$ min). VEGF, vWF and bFGF were detected using ELISA kits according to the manufacturer's instructions. The optical density of each well was determined using a microplate reader at $450 \mathrm{~nm}$. Duplicate assays were performed for each sample.

\section{Statistical analysis}

SPSS 13.0 software was used for the statistical analysis. Data are expressed as mean \pm standard deviation (SD), and multi-group comparisonwas performed using one-way ANOVA and pair-wise comparison (LSD method). $P<0.05$ was considered statistically significant.

\section{RESULTS}

\section{Morphological characteristics of EPCs}

MNCs began to adhere to wall and became large when seeded for $24 \mathrm{~h}$. Inverted microscope observation revealed that the transparency of the wall-adherent cells was enhanced. Moreover, the border became clear, and the cells became small rod-shaped or spindle. After cultivation for 7 days, the wall-adherent cells began the 'colonylike' proliferation with numerous spindle peripheral cells. In the second week, the spindle cells increased significantly. When cultured until the 28th day, the spindle cells adhered to one another and exhibited 'paving stone-like' arrangement.
EPCs that formed at different periods are shown in Figure 1. The EPCs cultured for 28 days were infected with adenovirus (the negative control and blank control groups were set at the same time). After $48 \mathrm{~h}$, the cell morphological observation under a fluorescence-inverted phase-contrast microscope revealed the expression of green fluorescent protein in the AdEGFP-hß-NGF and Ad-EGFP groups. However, the control group had no fluorescence. The infection effects in different groups are shown in Figure 2. One week after the infection, some cells exhibited neurosphere-like proliferation. However, the negative control and blank control groups showed no corresponding proliferation, as shown in Figure 3.

\section{Expression and detection of TrKA protein through Western blot}

After the cells were infected for $48 \mathrm{~h}$, the total cellular proteins were extracted for immunoblot assay. The results revealed that TrKA was significantly upregulated in the Ad-EGFP-hßNGF group than that in the Ad-EGFP and blank control groups $(P<0.01)$, as shown in Figure 4.

Detection of VEGF, vWF and bFGF levels in the culture supernatants through enzymelinked immunosorbent assay (ELISA)

After the EPCs were infected for 6 days, the cell culture media were collected for the detection of VEGF, vWF and bFGF through ELISA. All these
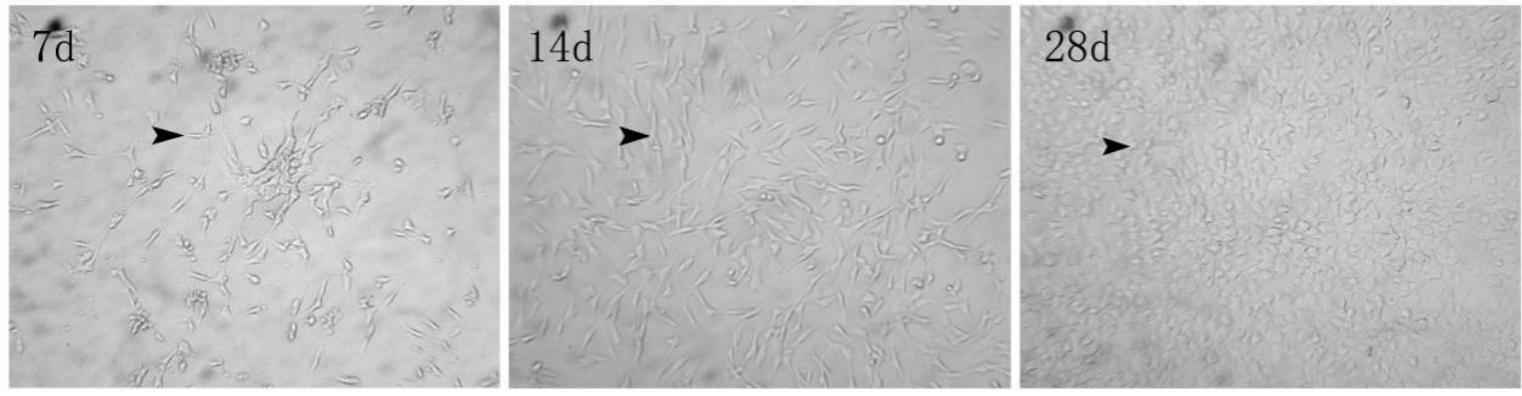

Figure 1: Morphological changes of EPCs at different stages
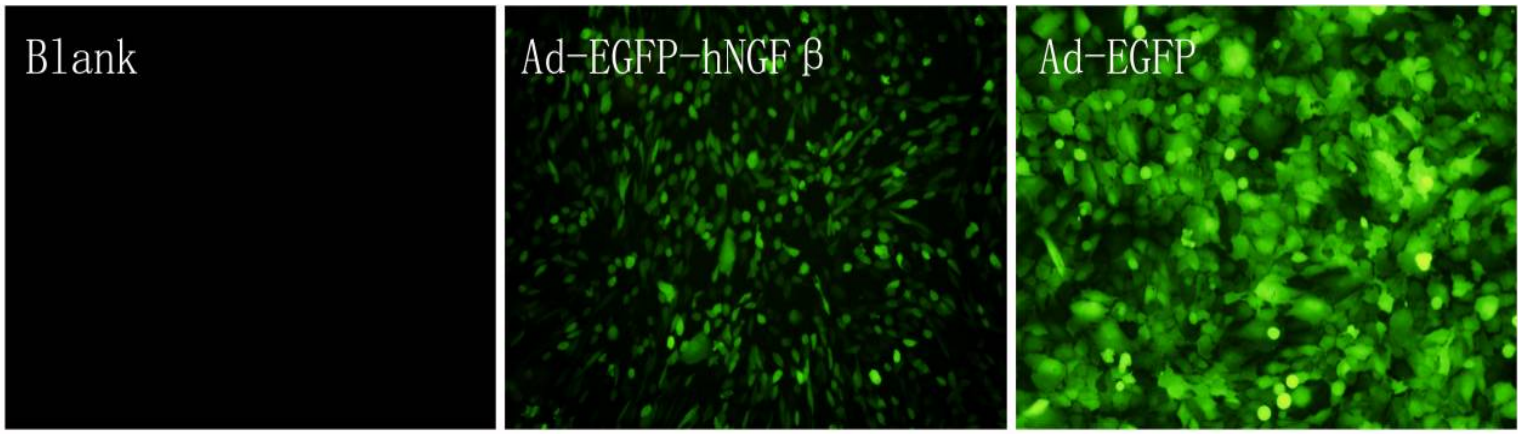

Figure 2: Expressions of green fluorescent protein in different groups 

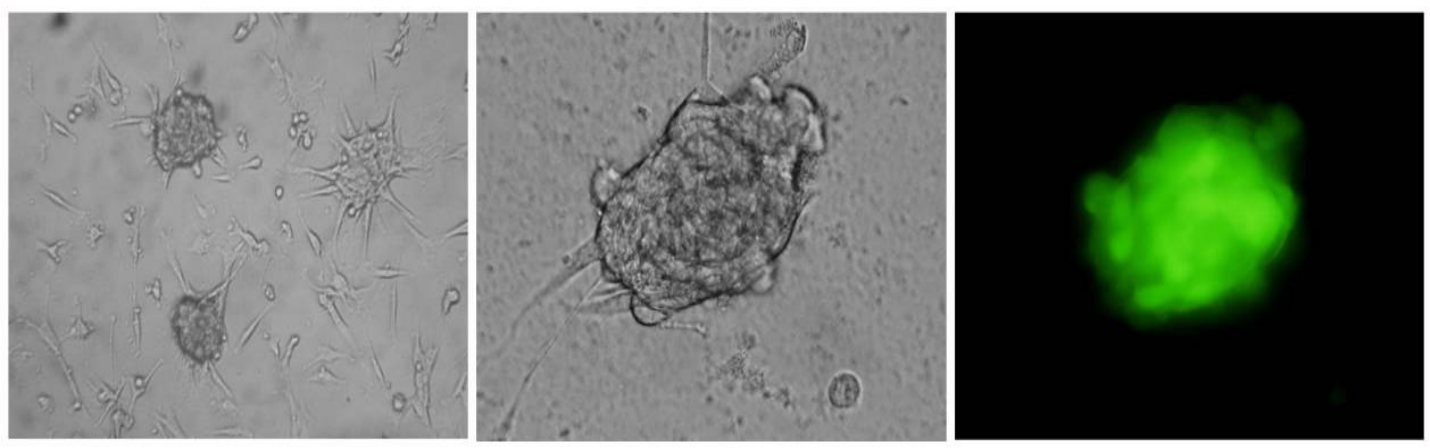

Figure 3: Cells exhibited neurosphere-like proliferation after infection with Ad-EGFP-h $\beta$-NGF for 1 week
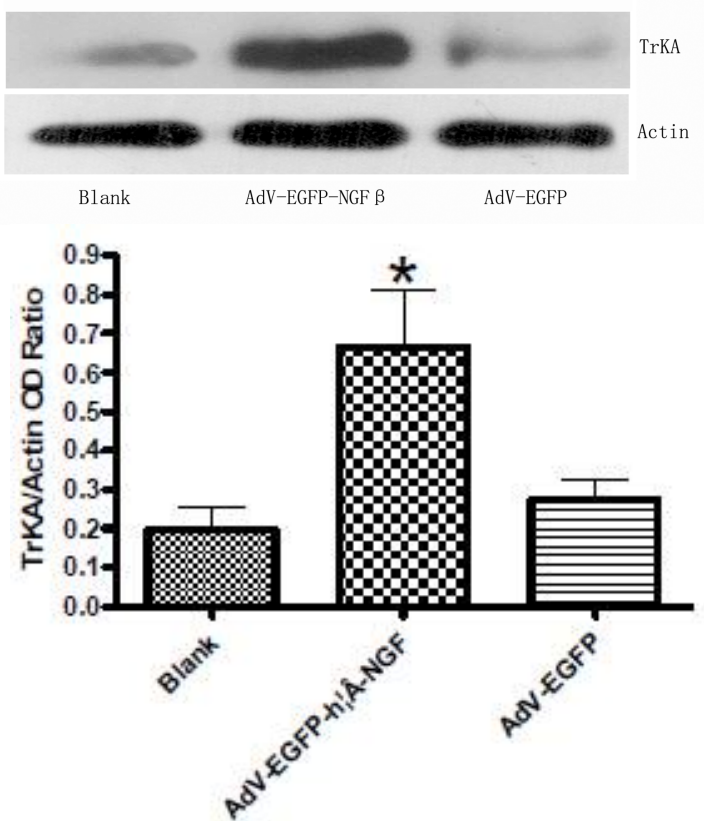

Figure 4: TrKA expression levels in different treatment groups

three factors in the Ad - EGFP - h $\beta$-NGF group were significantly upregulated compared with those in the Ad-EGFP and blank control groups $(P<0.01)$, as shown in Table 1.

\section{DISCUSSION}

EPCs are responsible for maintaining the dynamic equilibrium of endothelial injury and repair, and their quantity and functions are directly related to the occurrence and development of vascular diseases [8]. Under certain induction conditions, EPCs can promote angiogenesis in ischemic areas and increase collateral circulation. The proangiogenesis mechanisms of EPCs have been confirmed, which mainly include two aspects,(1) Selfproliferation and differentiation to form new blood vessels without reliance on the original organ system, (2) EPCs can secrete cytokines, such as VEGF or bFGF, thereby promoting the proliferation of local vascular endothelial cells via paracrine; in particular, the angiogenetic effects are enhanced, thereby improving blood supply [9]. During EPC differentiation, the regulation of proangiogenic factors and their receptors plays active roles, and they participate in different stages, amongst which the proangiogenetic effects of VEGF, bFGF and VWF have been demonstrated [10].

NGF is a nerve cell growth regulator that is firstly discovered amongst neurotrophic factors, and has important regulatory roles towards the development, differentiation, growth, regeneration and expression of functional properties of the central and peripheral neurons [11-13]. Recent studies have demonstrated that NGF directly promotes angiogenesis mainly through vascular endothelial cell-associated effects [14]. In this study, Ad - EGFP - h $\beta$-NGF and Ad-EGFP were successfully infected into rat EPCs, and we observed that all the cells adhered to wall grew in the control group. The cells also changed from fibroblast-like cells to epithelial cells with time. However, the differentiation rate of the cells in the Ad - EGFP - h $\beta$-NGF group decreased, but the proliferation rate increased. Some cells also exhibited neurosphere-like proliferation. These observations indicate that NGF could maintain and restore the features of EPCs, which are conducive in maintaining the EPC bank and providing adequate cell source for vascular repair and generation. After the EPCs were infected with NGF, cell proliferation was evident, showing similar roles of VEGF, bFGF or vWF; this phenomenon established the foundation for angiogenesis.

Several studies demonstrated that EPCs have two receptors, namely, TrKA and P75 neurotrophin receptor that mediate the signal transduction of NGF. The former possesses high affinity, whereas the latter has low affinity. The TrKA receptor generally mediates positive signals and mainly promotes cell survival and proliferation. When NGF binds the TrKA receptor, it can regulate the affinity of its receptor and the TrKA signal transduction. First, NGF 
Table 1: ELISA data for different groups (mean \pm SEM, $\mathrm{ng} / \mathrm{ml}$ )

\begin{tabular}{lccc}
\hline Group & VEGF & vWF & bFGF \\
\hline Blank & $0.185 \pm 0.057$ & $0.361 \pm 0.058$ & $0.394 \pm 0.029$ \\
Ad-EGFP-hß-NGF & $0.535 \pm 0.097^{\star}$ & $0.594 \pm 0.025^{*}$ & $0.682 \pm 0.068^{*}$ \\
Ad-EGFP & $0.204 \pm 0.076$ & $0.403 \pm 0.039$ & $0.349 \pm 0.057$ \\
\hline${ }^{*} P<0.01$ & & &
\end{tabular}

stimulates the expression and secretion of matrix metalloproteinase-2, thereby regulating phosphatidyl inositol 3-kinase (PI3K)/AKT signalling pathway by increasing the phosphorylation of TrKA and the activity of PI3K. Therefore, the main mechanism of NGF in angiogenesis is to exert its biological effects by binding its high-affinity receptor TrKA. At present, the capillaries and aortic endothelial cells in mice, as well as human umbilical vein endothelial cells, can produce NGF and express the TrKA protein. ELISA and immunohistochemical techniques are used to assess ischemic muscles; the endogenous NGF and its highaffinity receptor TrKA are upregulated, and the administration of exogenous NGF can significantly improve the limb ischemic conditions [15].

The results of this study showed that when rat EPCs were infected with Ad - EGFP - h $\beta$-NGF, the cells exhibited neurosphere-like proliferation, and the expression levels of VEGF, vWF, bFGF and TrKA protein in cell culture medium were significantly upregulated. Therefore, NGF may regulate the stem cell properties of EPCs, and the expression levels and secretions of proangiogenic factors (i.e., VEGF, vWF and bFGF) and TrKA protein may be upregulated, thereby promoting angiogenesis. However, the proangiogenetic abilities of NGF should still be confirmed by further experiments.

\section{CONCLUSION}

$\beta$-NGF upregulates the expression of TrKA receptor protein and the secretion of angiogenic growth factors (i.e., VEGF, vWF and bFGF), thereby promoting the differentiation of rat EPCs. This may contribute to angiopoiesis or vascular repair.

\section{DECLARATIONS}

\section{Acknowledgement}

The authors thank Tao Bao of Wuhan University, for expert technical assistance.

\section{Conflict of Interest}

No conflict of interest associated with this work.

\section{Contribution of Authors}

The authors declare that this work was done by the authors named in this article and all liabilities pertaining to claims relating to the content of this article will be borne by them.

\section{Open Access}

This is an Open Access article that uses a funding model which does not charge readers or their institutions for access and distributed under the terms of the Creative Commons Attribution License (http://creativecommons.org/licenses/by/ 4.0) and the Budapest Open Access Initiative (http://www.budapestopenaccessinitiative.org/rea d), which permit unrestricted use, distribution, and reproduction in any medium, provided the original work is properly credited.

\section{REFERENCES}

1. Kovacic JC, Moore J, Herbert A, Ma D, Boehm M, Graham RM. Endothelial progenitor cells, angioblasts, and angiogenesis-old terms reconsidered from a current perspective. Trends Cardiovasc Med 2008; 18: 45-51.

2. Berger S, Lavie L. Endothelial progenitor cells in cardiovascular disease and hypoxia--potential implications to obstructive sleep apnea. Transl Res 2011; 158: 1-13.

3. Wang ZJ, Zhao S, Wang $H X$. Risk factors for the occurrence of diabetes after hematopoietic stem cell transplantation for treating malignant hematopathy. $J$ Clinrehabil Tis Engin Res 2008; 12: 1457-1459.

4. Wang ZJ, Mao H, Ding S.Clinical observation on 36 patients with diabetic peripheral angiopathy after autologous hemopoietic stem cell transplantation. Chin J Postgrad Med 2008; 19: 8-11.

5. Fahnestock M. Structure and biosynthesis of nerve growth factor. Curr Top Microbiol Immunol 1991; 165: 126.

6. Wu J, Li JF, Ying QU, Chen XH, Tang YQ. Characterization and differentiation of mouse bone marrow-derived endothelial progenitor cells. Chinese $J$ Path 2011; 27: 1121-1126.

7. Goodman JR, Chandna A, Borch C. Does accreditation by the Association for Assessment and Accreditation of Laboratory Animal Care International (AAALAC) ensure greater compliance with animal welfare laws? J Appl Anim Welf Sci 2015; 18: 82-91. 
8. Zhou JL, Zhou MH, Chen YC, Zhou C, Shi JW. Coculture proliferation and migration of human umbilical cord blood-derived endothelial progenitor cells with vascular endothelial growth factor and basic fibroblast growth factor. J Clin Rehabil Tis Engin Res 2011; 15 : 1000-1004.

9. Hur J, Yoon $\mathrm{CH}$, Kim HS, Choi JH, Kang HJ, Hwang KK, Oh BH, Lee MM, Park YB. .Characterization of two types of endothelial progenitor cells and their different contributions to neovasculogenesis. Arterioscler Thromb Vasc Biol 2004; 24: 288-293.

10. Richardson MR, Yoder MC. Endothelial progenitor cells: quo vadis? J Mol Cell Cardiol 2011; 50: 266-272.

11. Kalka C, Masuda H, Takahashi T, Kalka-Moll WM, Silver $M$, Kearney $M$, Li $T$, Isner JM, Asahara $T$. Transplantation of ex vivo expanded endothelial progenitor cells for therapeutic neovascularization. Proc Natl Acad Sci USA 2000; 97: 3422-3427.
12. Murohara T, Ikeda H, Duan J, Shintani S, Sasaki Ki, Eguchi $H$, Onitsuka I, Matsui $K$, Imaizumi $T$. Transplanted cord blood-derived endothelial precursor cells augment postnatal neovascularization. J Clin Invest 2000; 105: 1527-1536.

13. Zhang YL, Fang JQ, Zhang WG, Chen J. Isolation, cultivation, and identification of endothelial progenitor cells from rabbit bone marrow. Chongqing Med 2011; 40: 952-953.

14. Pasquier E, Dias S. Endothelial progenitor cells: hope beyond controversy. Curr Cancer Drug Targets 2010; 10: 914-921.

15. Zhang JL, Zheng LP, Wang $H$. Impact of vascular endothelial growth factor and basic fibroblast growth factor on culture of rat peripheral blood progenitor cells. Chin J Nephrol 2010; 26: 915-919. 